\title{
Design of $\left(\mathrm{ZrO}_{2}\right)_{x} /\left(\mathrm{Cr}_{2} \mathrm{O}_{3}\right)_{y} /\left(\mathrm{Al}_{2} \mathrm{O}_{3}\right)_{1-x-y}$ superlattices for high transmittance APSM at $193 \mathrm{~nm}$ wavelength
}

\author{
F.D. Lai*, L.A. Wang \\ Department of Electrical Engineering and Institute of Electro-Optical Engineering, National Taiwan University, \\ Taipei, Taiwan
}

\begin{abstract}
A method for constructing a superlattice whose optical constant can be tuned over a wide range to meet the requirements of a HT-APSM blank is studied. $\left(\mathrm{ZrO}_{2}\right)_{x} /\left(\mathrm{Cr}_{2} \mathrm{O}_{3}\right)_{y} /\left(\mathrm{Al}_{2} \mathrm{O}_{3}\right)_{1-x-y}$ superlattices composed of 10 film stacks, which includes the stoichiometric $\mathrm{ZrO}_{2}, \mathrm{Cr}_{2} \mathrm{O}_{3}$ and $\mathrm{Al}_{2} \mathrm{O}_{3}$ layers in each stack, are obtained by using r.f. unbalanced magnetron sputtering in an atmosphere of argon and oxygen. One domain of thickness fraction of $\left(\mathrm{ZrO}_{2}, \mathrm{Cr}_{2} \mathrm{O}_{3}\right)$ for the $\left(\mathrm{ZrO}_{2}\right)_{x} /\left(\mathrm{Cr}_{2} \mathrm{O}_{3}\right)_{y} /\left(\mathrm{Al}_{2} \mathrm{O}_{3}\right)_{1-x-y}$ superlattices with an optimized transmittance of $18 \%$ is found to be bounded by $(0.09,0.22)$ and $(0.48,0.32)$. (C) 2002 Published by Elsevier Science B.V.
\end{abstract}

Keywords: Superlattice; $\mathrm{ZrO}_{2} ; \mathrm{Cr}_{2} \mathrm{O}_{3} ; \mathrm{Al}_{2} \mathrm{O}_{3}$

\section{Introduction}

An attenuated phase-shifting mask (APSM) could improve both resolution and depth of focus, and overcome the phase conflict issue incurred in a traditional phase-shifting mask. An APSM could be applied to any arbitrary mask patterns and is relatively easy in design and manufacturing. ArF lithography employing APSM would lead to nodes of $100 \mathrm{~nm}$ and even smaller ones [1]. Therefore, it can be implemented more easily as compared to other types of phase-shifting masks for fabricating high-density integrated circuits. A high transmittance APSM (HT-APSM) has become important because an increase of focus margin can be obtained as the photoresist technologies improve and the chrome assist features add. By employing HT-PSM for increasing resolution, ArF lithography may have the potential of reaching a 70-nm technology node.

Generally, the key optical requirements for a HT-APSM blank are (1) $180^{\circ}$ phase shift, (2) transmittance $(T)$ of $20 \pm 5 \%$ (with an optimized value of 18\%) [2], and (3) reflectance $(R)$ between $10 \%$ and $15 \%$. Though there are many material candidates for APSM, most of them have a limited tuning range of optical constant. A superlattice consists of two or more layers in each stack with

\footnotetext{
*Corresponding author.

E-mail address: lon@ccms.ntu.edu.tw (F.D. Lai).
} 
repeated stacks, of which the thickness is less than $10 \%$ of the working wavelength. The optical properties of a superlattice being less sensitive to details of layer interfaces can be well described by an effective medium theory [3]. Therefore, a superlattice with three or more layers in each stack will be a material candidate for a new HT-APSM.

The chemical composition and optical properties of non-stoichiometric films, for example $\mathrm{SiN}_{x}$ or $\mathrm{SiON}$, can be adjusted by changing the ratio of reactive gases (e.g. $\mathrm{O}_{2}, \mathrm{~N}_{2}$ ) in a plasma process. Due to local differences in pumping speeds for the reactive gases, the chemical composition and optical properties of non-stoichiometric films at the center and the sides of a mask may be slightly different. The film thickness is thus hard to determine as for a $\pi$-phase shifter. Nevertheless, stoichiometric films do not have such shortcomings.

In this work, the $\left(\mathrm{ZrO}_{2}\right)_{x} /\left(\mathrm{Cr}_{2} \mathrm{O}_{3}\right)_{y} /\left(\mathrm{Al}_{2} \mathrm{O}_{3}\right)_{1-x-y}$ superlattices with the stoichiometric $\mathrm{ZrO}_{2}, \mathrm{Cr}_{2} \mathrm{O}_{3}$ and $\mathrm{Al}_{2} \mathrm{O}_{3}$ layers in each film stack are aimed to meet the optical requirements of a HT-APSM blank material.

We report five main aspects in this paper.

1. A method for constructing a superlattice whose optical constant can be tuned over a wide range to cover the requirements of a HT-APSM blank is studied.

2. The dependences of the optical constant on the oxygen flow rate of $\mathrm{ZrO}_{2}, \mathrm{Al}_{2} \mathrm{O}_{3}$ and $\mathrm{Cr}_{2} \mathrm{O}_{3}$ thin films are studied and the stoichiometric $\mathrm{ZrO}_{2}, \mathrm{Cr}_{2} \mathrm{O}_{3}$ and $\mathrm{Al}_{2} \mathrm{O}_{3}$ thin films are prepared and identified by XPS.

3. Optical constants of $\left(\mathrm{ZrO}_{2}\right)_{x} /\left(\mathrm{Cr}_{2} \mathrm{O}_{3}\right)_{y} /\left(\mathrm{Al}_{2} \mathrm{O}_{3}\right)_{1-x-y}$ superlattices consisting of three layers, $\mathrm{ZrO}_{2}$, $\mathrm{Cr}_{2} \mathrm{O}_{3}$ and $\mathrm{Al}_{2} \mathrm{O}_{3}$, in each film stack are calculated.

4. One domain of thickness fraction of $\left(\mathrm{ZrO}_{2}, \mathrm{Cr}_{2} \mathrm{O}_{3}\right)$ for the $\left(\mathrm{ZrO}_{2}\right)_{x} /\left(\mathrm{Cr}_{2} \mathrm{O}_{3}\right)_{y} /\left(\mathrm{Al}_{2} \mathrm{O}_{3}\right)_{1-x-y}$ superlattices that meets the optical requirements of a HT-APSM is found. And one area of thickness fraction of $\left(\mathrm{ZrO}_{2}, \mathrm{Cr}_{2} \mathrm{O}_{3}\right)$ for the $\left(\mathrm{ZrO}_{2}\right)_{x} /\left(\mathrm{Cr}_{2} \mathrm{O}_{3}\right)_{y} /\left(\mathrm{Al}_{2} \mathrm{O}_{3}\right)_{1-x-y}$ superlattices with an optimized transmittance of $18 \%$ is also found.

5. The $\left(\mathrm{ZrO}_{2}\right)_{x} /\left(\mathrm{Cr}_{2} \mathrm{O}_{3}\right)_{y} /\left(\mathrm{Al}_{2} \mathrm{O}_{3}\right)_{1-x-y}$ superlattices with an optimized transmittance of $18 \%$ are fabricated and their optical properties are also studied.

\section{Experiment}

$\left(\mathrm{ZrO}_{2}\right)_{x} /\left(\mathrm{Cr}_{2} \mathrm{O}_{3}\right)_{y} /\left(\mathrm{Al}_{2} \mathrm{O}_{3}\right)_{1-x-y}$ superlattices are deposited on UV grade fused silica substrates $(n=1.561$ at $193 \mathrm{~nm})$ by using dual-gun r.f. reactive unbalanced magnetron sputtering in an atmosphere of argon and oxygen. The substrates have surface flatness of $\lambda / 10(\lambda=632.8 \mathrm{~nm})$ and their rotations are controlled by a computer. Target materials are zirconium (99.99\% purity), chromium (99.99\% purity) and aluminium (99.999\% purity). All films are deposited according to the following parameters: 8 mTorr pressure, $10 \mathrm{sccm}$ Ar flow rate, $20 \mathrm{sccm} \mathrm{O}_{2}$ flow rate, $70 \mathrm{~W}$ sputtering power for $\mathrm{Zr}, 20 \mathrm{~W}$ for $\mathrm{Cr}$ and $85 \mathrm{~W}$ for $\mathrm{Al}$ targets. The chemical compositions of $\mathrm{ZrO}_{2}, \mathrm{Cr}_{2} \mathrm{O}_{3}$ and $\mathrm{Al}_{2} \mathrm{O}_{3}$ thin films are identified by utilizing XPS. The deposition rate of the thin films is determined by measuring the film thickness using an atomic force microscope (AFM). The reflectance and transmittance are measured by an optical spectrometer (Hitachi, U3501). The refractive index $n$ and extinction coefficient $k$ of the films are obtained by the reflection-transmittance $(R-T)$ method in which the multiple reflection effects are taken into account. The film thickness for a $\left(\mathrm{ZrO}_{2}\right)_{x} /$ 
$\left(\mathrm{Cr}_{2} \mathrm{O}_{3}\right)_{y} /\left(\mathrm{Al}_{2} \mathrm{O}_{3}\right)_{1-x-y}$ superlattice to have an optimized transmittance of $18 \%$ is calculated by employing the effective medium theory based on the measured optical constants of $\mathrm{ZrO}_{2}, \mathrm{Cr}_{2} \mathrm{O}_{3}$ and $\mathrm{Al}_{2} \mathrm{O}_{3}$ films. $\left(\mathrm{ZrO}_{2}\right)_{x} /\left(\mathrm{Cr}_{2} \mathrm{O}_{3}\right)_{y} /\left(\mathrm{Al}_{2} \mathrm{O}_{3}\right)_{1-x-y}$ superlattices are composed of 10 such film stacks. The optical constants of $\left(\mathrm{ZrO}_{2}\right)_{x} /\left(\mathrm{Cr}_{2} \mathrm{O}_{3}\right)_{y} /\left(\mathrm{Al}_{2} \mathrm{O}_{3}\right)_{1-x-y}$ superlattices are determined by each layer's thickness, which is controlled by deposition rate and time.

\section{Results and discussion}

3.1. A method for constructing a superlattice whose optical constant can be tuned over a wide range to meet the optical requirements of a HT-APSM blank

Assume each stack of a superlattice has $n$ layers. The dielectric constant of a superlattice satisfying the effective medium theory [3] can be expressed as

$$
\begin{aligned}
& \varepsilon\left(x_{1}, x_{2}, x_{3}, \ldots, x_{n}\right)=x_{1} \varepsilon_{1}+x_{2} \varepsilon_{2}+x_{3} \varepsilon_{3}+\cdots+x_{n} \varepsilon_{n} \\
& x_{1}+x_{2}+x_{3}+\cdots+x_{n}=1
\end{aligned}
$$

where $\varepsilon\left(x_{1}, x_{2}, x_{3}, \ldots, x_{n}\right) \varepsilon_{1}, \varepsilon_{2}, \varepsilon_{3} \ldots$ and $\varepsilon_{n}$ are, respectively, complex dielectric constants of the superlattice $x_{1} x_{2} x_{3} \ldots x_{n}$, layer 1 , layer 2 , layer $3 \ldots$ and layer $n$. And $x_{1}, x_{2}, x_{3} \ldots$ and $x_{n}$ are, respectively, the thickness fractions of layer 1 , layer 2, layer $3 \ldots$ and layer $n$ in the $x_{1} x_{2} x_{3} \ldots x_{n}$ film stack.

Schematically shown in Fig. 1 is the boundary of the optical-constant domain that meets the optical

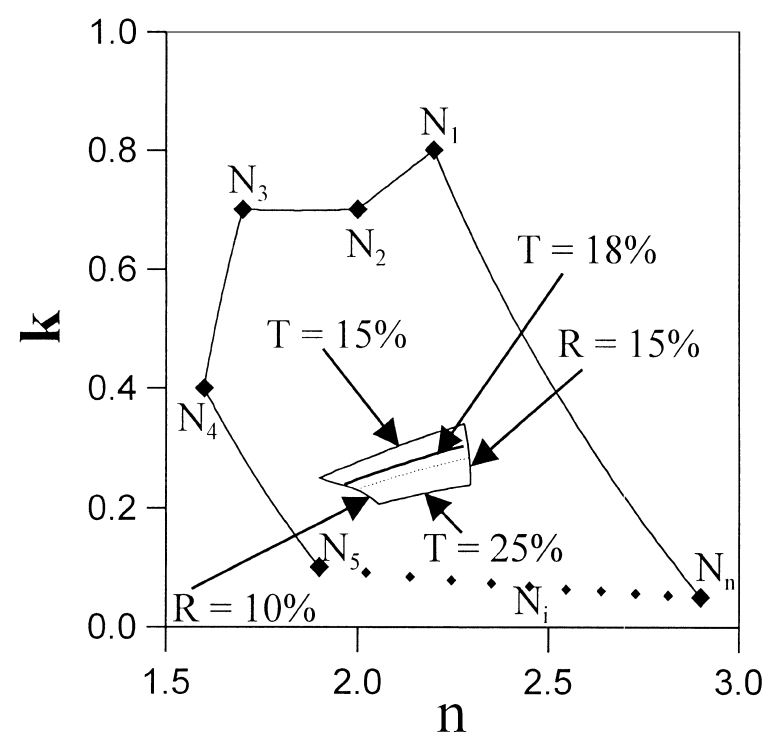

Fig. 1. A diagram schematically shows the curves connecting the optical constants $N_{1}, N_{2}, N_{3} \ldots N_{i} \ldots N_{n}$ of $n$ layers in each stack for a superlattice form an $n-k$ area that encompasses the desired optical constant domain of a HT-APSM. 
requirements of $R$ and $T$. Assume optical constants of layer 1, 2, 3 . and $n$ in each stack of a superlattice are $N_{1}$ (i.e. $\left.\varepsilon_{1}=\left(n_{1}-i k_{1}\right)^{2}=\left(N_{1}\right)^{2}\right), N_{2}, N_{3} \ldots$ and $N_{n}$, respectively. Each optical constant forms a point in the $n-k$ plot. The optical constant of any point bounded on and within the curves $\left(N_{1}, N_{2}\right),\left(N_{2}, N_{3}\right), \ldots$ and $\left(N_{n-1}, N_{n}\right)$ can be calculated by employing the effective medium

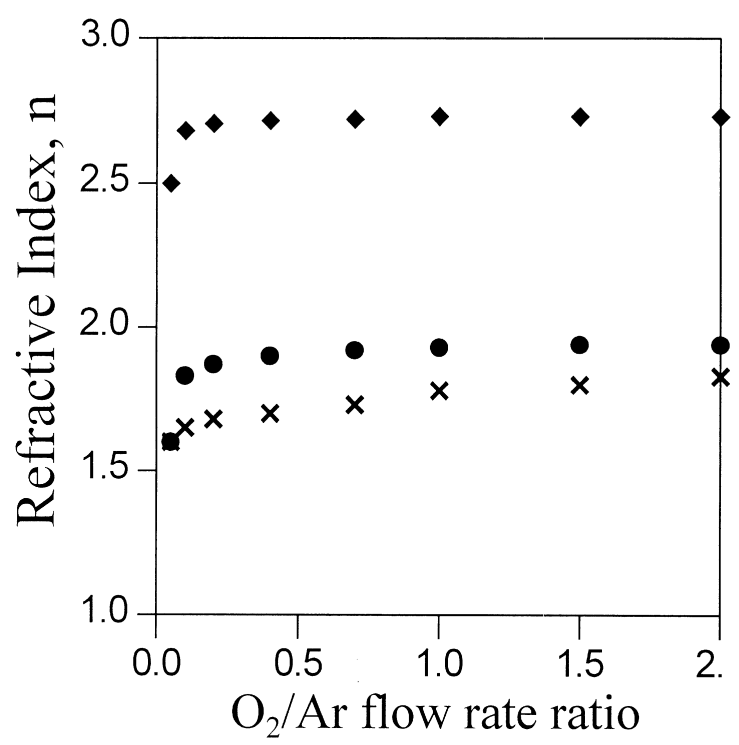

(a)

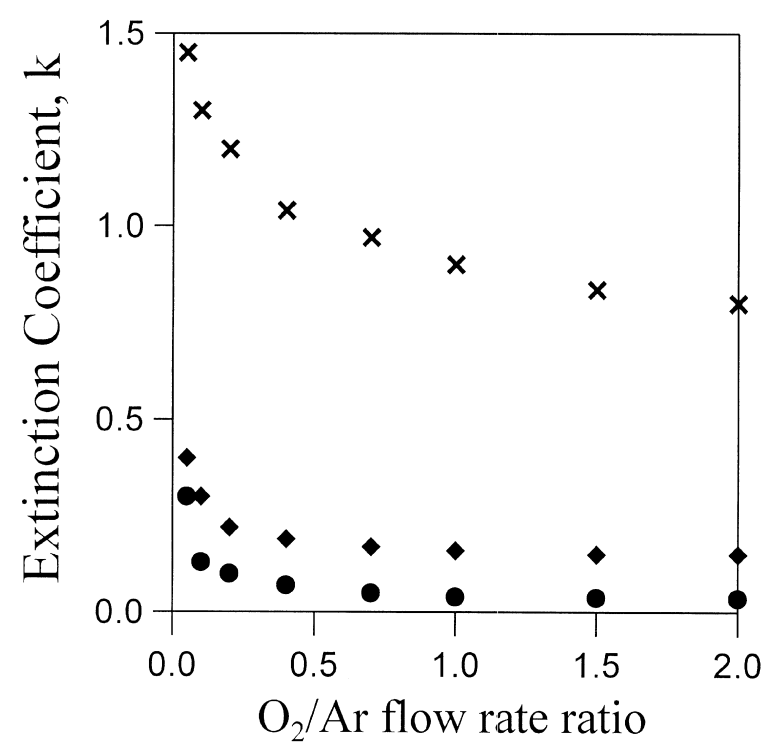

(b)

Fig. 2. Variations of (a) extinction coefficient and (b) refractive index of $\mathrm{ZrO}_{2}(\diamond), \mathrm{Cr}_{2} \mathrm{O}_{3}(\times)$ and $\mathrm{Al}_{2} \mathrm{O}_{3}(\bullet)$ films with $\mathrm{O}_{2} /$ Ar flow rate ratios. 
theory. If the bounded area of optical constants encompasses the required $n-k$ domain of a HT-APSM, a superlattice having these layers $\left(N_{1}, N_{2}, \ldots, N_{i}, \ldots, N_{n}\right)$ in each stack can be constructed to realize the HT-APSM. Materials such as $\mathrm{ZrO}_{2}, \mathrm{Cr}_{2} \mathrm{O}_{3}, \mathrm{Al}_{2} \mathrm{O}_{3}, \mathrm{Si}_{2} \mathrm{O}_{3}, \mathrm{MoSiO}, \mathrm{TaSiO}$, $\mathrm{ZrSiO}, \mathrm{AlN}, \mathrm{CrN}$ and so on can be used as $N_{i}$.

\subsection{Optical property and chemical composition analysis of $\mathrm{ZrO}_{2}, \mathrm{Cr}_{2} \mathrm{O}_{3}$ and $\mathrm{Al}_{2} \mathrm{O}_{3}$ thin films}

Fig. 2 shows that as $\mathrm{O}_{2} / \mathrm{Ar}$ flow rate ratio increases the extinction coefficient becomes lower and the refractive index higher. The absorption is higher at low $\mathrm{O}_{2} /$ Ar flow rate ratios because some not completely oxidized atoms are left. So, superlattices are deposited at the highest $\mathrm{O}_{2} /$ Ar flow rate ratio.

Binding energies of $\mathrm{Zr} 3 \mathrm{~d}_{5 / 2}, \mathrm{Cr} 2 \mathrm{p}_{3 / 2}$ and $\mathrm{Al} 2 \mathrm{p}_{3 / 2}$ in the thin films and superlattices deposited at highest $\mathrm{O}_{2}$ /Ar flow rate ratio are identified by XPS in accordance with the theoretical XPS spectra [5] of $\mathrm{ZrO}_{2}, \mathrm{Cr}_{2} \mathrm{O}_{3}$ and $\mathrm{Al}_{2} \mathrm{O}_{3}$. The ratios of $\mathrm{O} / \mathrm{Zr}, \mathrm{O} / \mathrm{Cr}$ and $\mathrm{O} / \mathrm{Al}$ in those thin films identified by XPS are, respectively, 2.05 $\pm 0.08,1.56 \pm 0.07$ and 1.47 \pm 0.1 . Thus, the deposited $\mathrm{Al}_{2} \mathrm{O}_{3}, \mathrm{Cr}_{2} \mathrm{O}_{3}$ and $\mathrm{ZrO}_{2}$ thin films are stoichiometric.

The measured refractive indices and extinction coefficients of $\mathrm{ZrO}_{2}, \mathrm{Cr}_{2} \mathrm{O}_{3}$ and $\mathrm{Al}_{2} \mathrm{O}_{3}$ thin films are shown in Fig. 3.

3.3. Calculated domain for optical requirements of a HT-APSM blank based on $(\mathrm{ZrO})_{2}$ I $\left(\mathrm{Cr}_{2} \mathrm{O}_{3}\right)_{y} /\left(\mathrm{Al}_{2} \mathrm{O}_{3}\right)_{1-x-y}$ superlattice

The calculated optical constants of $\left(\mathrm{ZrO}_{2}\right)_{x} /\left(\mathrm{Cr}_{2} \mathrm{O}_{3}\right)_{y} /\left(\mathrm{Al}_{2} \mathrm{O}_{3}\right)_{1-x-y}$ superlattices [4] by employing Eq. (1) with the measured optical constants of $\mathrm{ZrO}_{2}, \mathrm{Cr}_{2} \mathrm{O}_{3}$ and $\mathrm{Al}_{2} \mathrm{O}_{3}$ films are shown in Fig. 3. The

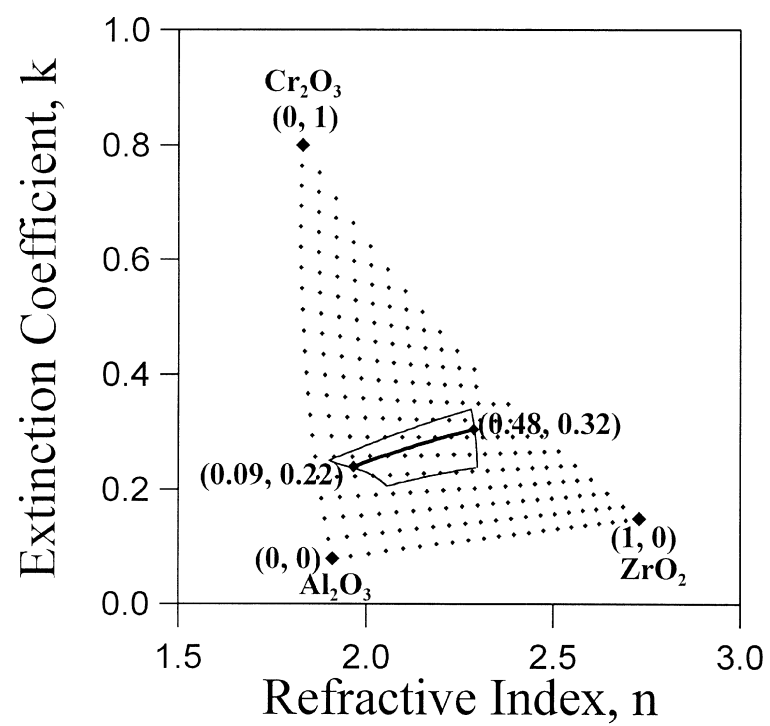

Fig. 3. Calculated optical constants of $\left(\mathrm{ZrO}_{2}\right)_{x} /\left(\mathrm{Cr}_{2} \mathrm{O}_{3}\right)_{y} /\left(\mathrm{Al}_{2} \mathrm{O}_{3}\right)_{1-x-y}$ superlattice on thickness fractions of $\mathrm{ZrO}_{2}, \mathrm{Cr}_{2} \mathrm{O}_{3}$ and $\mathrm{Al}_{2} \mathrm{O}_{3}$ from the measured optical constants of $\mathrm{ZrO}_{2}, \mathrm{Cr}_{2} \mathrm{O}_{3}$ and $\mathrm{Al}_{2} \mathrm{O}_{3}$ films. Calculated domain of thickness fraction of $\left(\mathrm{ZrO}_{2}, \mathrm{Cr}_{2} \mathrm{O}_{3}\right)$ for $\left(\mathrm{ZrO}_{2}\right)_{x} /\left(\mathrm{Cr}_{2} \mathrm{O}_{3}\right)_{y} /\left(\mathrm{Al}_{2} \mathrm{O}_{3}\right)_{1-x-y}$ superlattices with an optimized transmittance of $18 \%$ is also shown. 
bounded area of optical constants of $\left(\mathrm{ZrO}_{2}\right)_{x} /\left(\mathrm{Cr}_{2} \mathrm{O}_{3}\right)_{y} /\left(\mathrm{Al}_{2} \mathrm{O}_{3}\right)_{1-x-y}$ superlattices encompasses the required $n-k$ domain of HT-APSM. Therefore, $\left(\mathrm{ZrO}_{2}\right)_{x} /\left(\mathrm{Cr}_{2} \mathrm{O}_{3}\right)_{y} /\left(\mathrm{Al}_{2} \mathrm{O}_{3}\right)_{1-x-y}$ superlattices may be used to design a desirable HT-APSM.

Let $(x, y)$ represent an arbitrary point in the $X-Y$ diagram, in which $x$ and $y$ refer to, respectively, the thickness fraction of $\mathrm{ZrO}_{2}$ and $\mathrm{Cr}_{2} \mathrm{O}_{3}$ in a $\left(\mathrm{ZrO}_{2}\right)_{x} /\left(\mathrm{Cr}_{2} \mathrm{O}_{3}\right)_{y} /\left(\mathrm{Al}_{2} \mathrm{O}_{3}\right)_{1-x-y}$ film stack. $(0,0),(1$, $0)$ and $(0,1)$ indicate, respectively, the points of the $100 \%$ thickness of $\mathrm{Al}_{2} \mathrm{O}_{3}, \mathrm{ZrO}_{2}$ and $\mathrm{Cr}_{2} \mathrm{O}_{3}$ in the $X-Y$ diagram as shown in Fig. 3. Therefore, a quadrangular area, representing the requirement of $n-k$ values for a HT-APSM blank in ArF lithography, is calculated to be bounded by $(0.04,0.24)$, $(0.47,0.38),(0.18,0.17)$ and $(0.47,0.21)$ as shown in Fig. 3. And one domain of the thickness fraction of $\left(\mathrm{ZrO}_{2}, \mathrm{Cr}_{2} \mathrm{O}_{3}\right)$ for the $\left(\mathrm{ZrO}_{2}\right)_{x} /\left(\mathrm{Cr}_{2} \mathrm{O}_{3}\right)_{y} /\left(\mathrm{Al}_{2} \mathrm{O}_{3}\right)_{1-x-y}$ superlattices with an optimized transmittance of $18 \%$ is also found to be bounded by $(0.09,0.22)$ and $(0.48,0.32)$ as shown in Fig. 3.

\subsection{Measured optical properties of $\left(\mathrm{ZrO}_{2}\right)_{x} /\left(\mathrm{Cr}_{2} \mathrm{O}_{3}\right)_{y} /\left(\mathrm{Al}_{2} \mathrm{O}_{3}\right)_{1-x-y}$ superlattices with high transmittance of $18 \%$}

As illustrated in Fig. 4a, within the thickness fraction of $\mathrm{ZrO}_{2}$ the transmittances of $\left(\mathrm{ZrO}_{2}\right)_{x} /$ $\left(\mathrm{Cr}_{2} \mathrm{O}_{3}\right)_{y} /\left(\mathrm{Al}_{2} \mathrm{O}_{3}\right)_{1-x-y}$ superlattices remain about $18 \%$, and the reflectances increase with the thickness fraction of $\mathrm{ZrO}_{2}$. Meanwhile, the refractive indices and the extinction coefficients of $\left(\mathrm{ZrO}_{2}\right)_{x} /\left(\mathrm{Cr}_{2} \mathrm{O}_{3}\right)_{y} /\left(\mathrm{Al}_{2} \mathrm{O}_{3}\right)_{1-x-y}$ superlattices increase with the thickness fraction of $\mathrm{ZrO}_{2}$ shown in Fig. 4b. This is because the refractive index of $\mathrm{Al}_{2} \mathrm{O}_{3}$ is less than that of $\mathrm{ZrO}_{2}$. The calculated and measured optical constants of $\left(\mathrm{ZrO}_{2}\right)_{x} /\left(\mathrm{Cr}_{2} \mathrm{O}_{3}\right)_{y} /\left(\mathrm{Al}_{2} \mathrm{O}_{3}\right)_{1-x-y}$ superlattices with high transmittance of $18 \%$ are shown in Fig. 5. As shown in Fig. 6, the linear relationship of both $n^{2}-k^{2}$ and $2 n k$ to the thickness fraction of $\mathrm{ZrO}_{2}$ for $\left(\mathrm{ZrO}_{2}\right)_{x} /\left(\mathrm{Cr}_{2} \mathrm{O}_{3}\right)_{y} /\left(\mathrm{Al}_{2} \mathrm{O}_{3}\right)_{1-x-y}$ superlattices with high transmittance of $18 \%$ has been verified. The dielectric constant of $\left(\mathrm{ZrO}_{2}\right)_{x} /\left(\mathrm{Cr}_{2} \mathrm{O}_{3}\right)_{y} /\left(\mathrm{Al}_{2} \mathrm{O}_{3}\right)_{1-x-y}$ superlattices meets the effective medium theory. Therefore, $\left(\mathrm{ZrO}_{2}\right)_{x} /\left(\mathrm{Cr}_{2} \mathrm{O}_{3}\right)_{y} /\left(\mathrm{Al}_{2} \mathrm{O}_{3}\right)_{1-x-y}$ superlattices with wide range tunable dielectric constants can be used to design a desirable HT-APSM; that is, any optical constants suitable for HT-APSM can be determined from $\left(\mathrm{ZrO}_{2}\right)_{x} /\left(\mathrm{Cr}_{2} \mathrm{O}_{3}\right)_{y} /\left(\mathrm{Al}_{2} \mathrm{O}_{3}\right)_{1-x-y}$ superlattices.

\section{Conclusion}

A method for constructing a superlattice whose optical constant can be tuned over a wide range to cover the requirements of a HT-APSM blank is studied. The optical constant of any point bounded on and within the curves $\left(N_{1}, N_{2}\right),\left(N_{2}, N_{3}\right), \ldots$ and $\left(N_{n-1}, N_{n}\right)$ can be calculated by employing the effective medium theory. If the bounded area of optical constants encompasses the required $n-k$ domain of HT-APSM, a superlattice having these layers $\left(N_{1}, N_{2}, \ldots, N_{i}, \ldots, N_{n}\right)$ in each stack can be constructed to realize the HT-APSM. Optical constants of three-layer $\left(N_{1}, N_{2}, N_{3}\right)$ superlattice consisting of $\left(\mathrm{ZrO}_{2}, \mathrm{Cr}_{2} \mathrm{O}_{3}, \mathrm{Al}_{2} \mathrm{O}_{3}\right)$ compound materials are simulated. And it is found that the bounded area of optical constants of $\left(\mathrm{ZrO}_{2}\right)_{x} /\left(\mathrm{Cr}_{2} \mathrm{O}_{3}\right)_{y} /\left(\mathrm{Al}_{2} \mathrm{O}_{3}\right)_{1-x-y}$ superlattice encompasses the required $n-k$ domain of HT-APSM. One domain of thickness fraction of $\left(\mathrm{ZrO}_{2}, \mathrm{Cr}_{2} \mathrm{O}_{3}\right)$ for the 


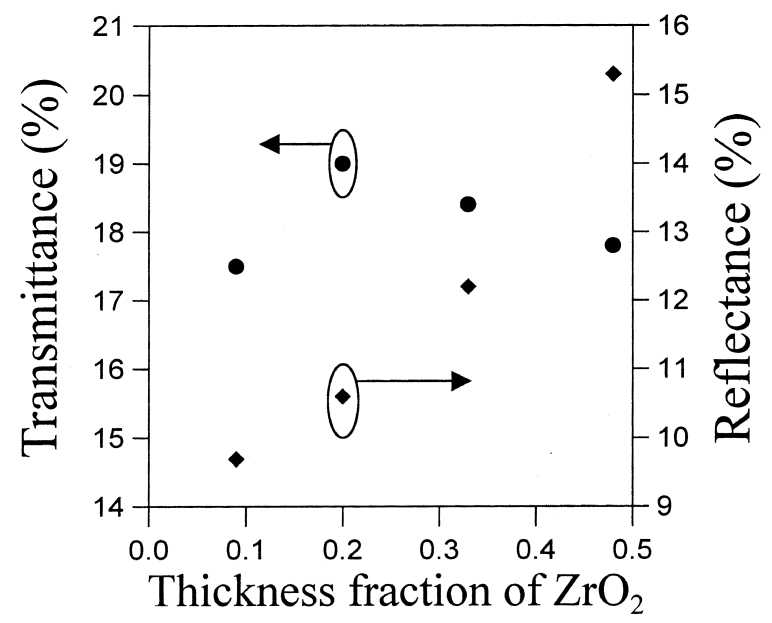

(a)

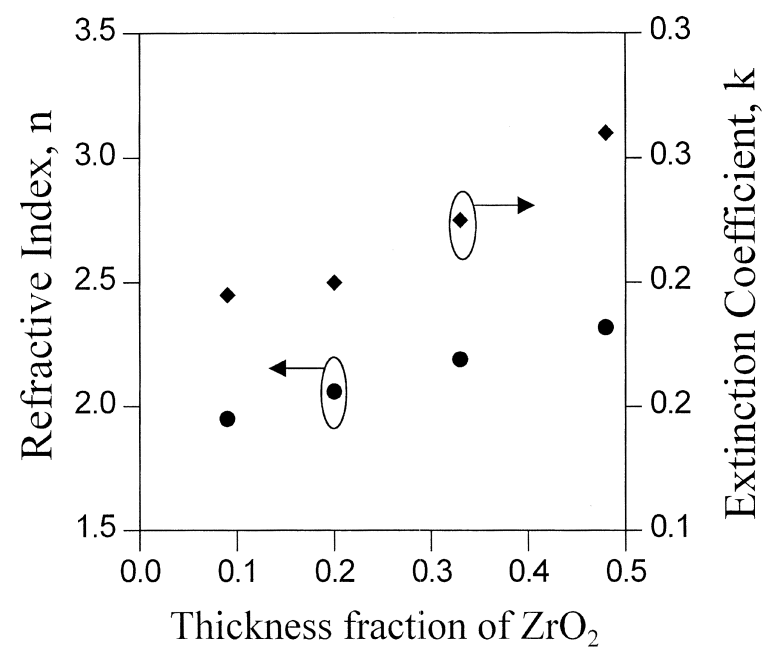

(b)

Fig. 4. Variations of (a) transmittance and reflectance and (b) optical constants of dielectric constants with thickness fraction of $\mathrm{ZrO}_{2}$ for $\left(\mathrm{ZrO}_{2}\right)_{x} /\left(\mathrm{Cr}_{2} \mathrm{O}_{3}\right)_{y} /\left(\mathrm{Al}_{2} \mathrm{O}_{3}\right)_{1-x-y}$ superlattices with an optimized transmittance of $18 \%$.

$\left(\mathrm{ZrO}_{2}\right)_{x} /\left(\mathrm{Cr}_{2} \mathrm{O}_{3}\right)_{y} /\left(\mathrm{Al}_{2} \mathrm{O}_{3}\right)_{1-x-y}$ superlattices with an optimized transmittance of $18 \%$ is also found to be bounded by $(0.09,0.22)$ and $(0.48,0.32)$. The $\left(\mathrm{ZrO}_{2}\right)_{x} /\left(\mathrm{Cr}_{2} \mathrm{O}_{3}\right)_{y} /\left(\mathrm{Al}_{2} \mathrm{O}_{3}\right)_{1-x-y}$ superlattices with an optimized transmittance of $18 \%$ are fabricated and their optical properties are also studied. The good agreement of the calculated and measured optical constants of $\left(\mathrm{ZrO}_{2}\right)_{x} /\left(\mathrm{Cr}_{2} \mathrm{O}_{3}\right)_{y} /$ $\left(\mathrm{Al}_{2} \mathrm{O}_{3}\right)_{1-x-y}$ superlattices with high transmittance of $18 \%$ has been shown. So, $\left(\mathrm{ZrO}_{2}\right)_{x} /\left(\mathrm{Cr}_{2} \mathrm{O}_{3}\right)_{y} /$ $\left(\mathrm{Al}_{2} \mathrm{O}_{3}\right)_{1-x-y}$ superlattices with wide range tunable dielectric constants can be easily used to design a desirable HT-APSM. 


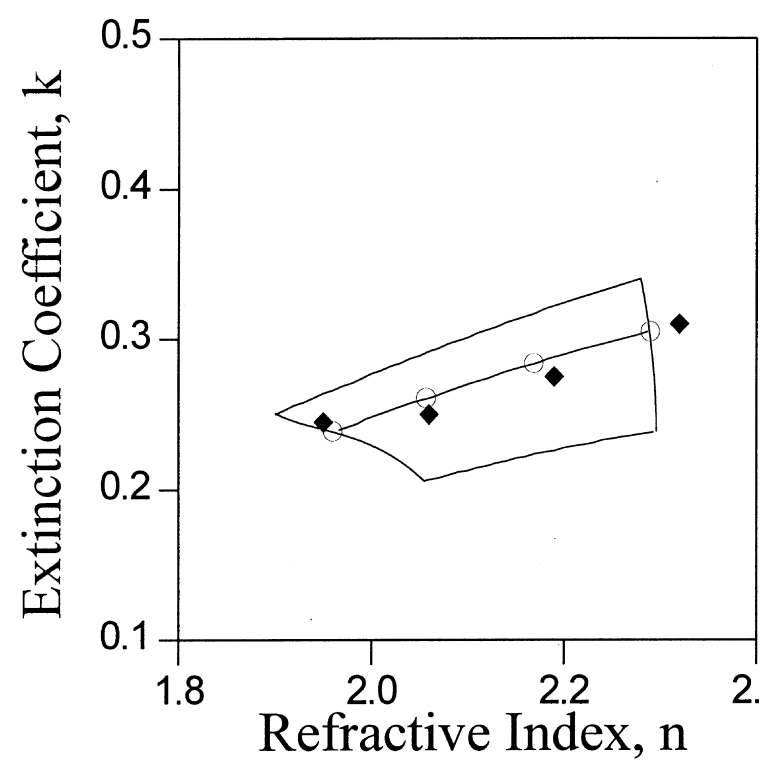

Fig. 5. Calculated $(\bigcirc)$ and measured $(\diamond)$ optical constants of $\left(\mathrm{ZrO}_{2}\right)_{x} /\left(\mathrm{Cr}_{2} \mathrm{O}_{3}\right)_{y} /\left(\mathrm{Al}_{2} \mathrm{O}_{3}\right)_{1-x-y}$ superlattices with an optimized transmittance of $18 \%$.

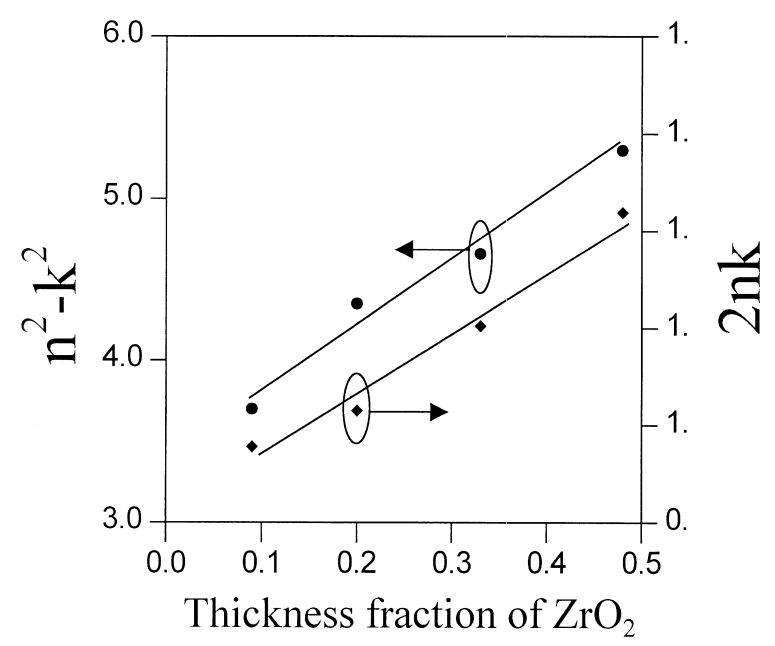

Fig. 6. Variations of real $\left(n^{2}-k^{2}\right)$ and imaginary $(2 n k)$ parts of dielectric constants with thickness fraction of $\mathrm{ZrO}_{2}$ for $\left(\mathrm{ZrO}_{2}\right)_{x} /\left(\mathrm{Cr}_{2} \mathrm{O}_{3}\right)_{y} /\left(\mathrm{Al}_{2} \mathrm{O}_{3}\right)_{1-x-y}$ superlattices with an optimized transmittance of $18 \%$.

\section{References}

[1] http://notes.sematech.org/1999_SIA_Roadmap/Home.htm

[2] R.J. Socha, J.S. Petersen, F. Chen, T. Laiding, K. Wampler, R. Caldwell, SPIE 3546 (1998) 617.

[3] O. Hunderi, J. Wave-Mater. Interact. 2 (1987) 29.

[4] F.D. Lai, L.A. Wang, J. Vac. Sci. Technol. B 19 (6) (2001) 2617.

[5] C.D. Wangner, W.M. Riggs, L.E. Davis, J.F. Moulder, G.E. Muilenberg, Handbook of X-ray Photoelectron 